\title{
Gather.town: an opportunity for self-paced learning in a synchronous, distance- learning environment
}

\author{
Colin D McClure*, Paul N Williams \\ Queen's University Belfast, Belfast, Northern Ireland \\ * Corresponding author
}

Keywords: Self-paced learning, distance-learning, COVID-19, video-conferencing, synchronous video-conferencing

\begin{abstract}
The COVID-19 pandemic has forced higher education to adopt distance-learning approaches in traditionally face-to-face and practical-based fields such as the health and life sciences. Such an abrupt change to distance-learning contexts brings a variety of challenges to student learning communities and makes it all the more important to ensure that key skills are effectively transferred. That students have only limited opportunities at the time of their learning to discuss their individual needs with their educators and peers is a particular cause for concern. Proximity-based video-conferencing platforms such as 'Gather' (gather.town) can offer a unique opportunity for learners to interact, at their own pace, with educators, peers and pre-developed materials, to tailor the teaching experience and develop these relationships in a distance-learning context. In this case study, the concepts and practice of statistical analysis using the software ' $R$ ' are introduced to thirty-eight university students via gather.town. By means of private spaces, pre-recorded videos and demonstrators, students are trained in both the concepts and practical skills to undertake data analysis at a pace they themselves determine. Both students and demonstrators provide their opinions on the effectiveness of the platform and identify its benefits, preferring it to alternative online systems such as MS Teams for their educational sessions.
\end{abstract}

\section{Background}

Higher education institutions (HEls) must constantly adapt to environmental and economic changes to ensure they meet their responsibilities to both their students and wider society. At a time when the global financial situation for higher education (HE) favours a low-cost, highfee model and when the number of versatile digital learning platforms has significantly grown, universities have increasingly adopted distance-learning (DL) to create a more sustainable economic system (Harry and Perraton, 1999). Such motivation has led to a steady rise in the number of American universities offering online degree courses, from $70 \%$ in 2012 to $76 \%$ by 2016 (Xu and $X u, 2017$ ). Within the United Kingdom (UK), between 2011 and 2015, the numbers of overseas students studying online degrees increased - by $26 \%$ from the USA, 41\% from Canada, 125\% from Australia and 135\% from South Africa (Vickers, 2017), so demonstrating a growing global demand for universities to meet. 
In such an economic landscape, the COVID-19 pandemic has forced universities to adopt DL approaches (Dhawan, 2020). Since the initial national lockdown in March 2020, practically all teaching within UK HEls has adapted to a DL-based approach, bringing many challenges, particularly for traditionally practical-based subjects such as the health and life sciences (Dost, 2020).

DL is defined as "providing education to students who are separated by distance (i.e., who are not physically present in the same space) and in which the pedagogical material is planned and prepared by an educational institution" (Kaplan and Haenlein, 2016, p.443), often taking a blended approach with both synchronous - i.e., learners engaged at the same time, usually via synchronous video-conferencing (SVC) (Themeli, 2016) - and asynchronous sessions to support students' learning. Although students generally show a greater preference for synchronous settings over asynchronous (Kemp and Grieve, 2014), the latter provide autonomy for students in the progression of their work, enabling self-paced learning for the individual (Azizan, 2010). This is particularly true for DL scenarios, as synchronous sessions - now often delivered via static, SVC software such as Microsoft (MS) Teams - offer little opportunity for individual educator-student contact, tailored-learning or peer-to-peer interactions (Themeli, 2016), although effective examples may be achieved using such features as breakout rooms to facilitate small-group interaction and instruction (Al-Samarraie, 2019). Fostering and encouraging meaningful formal (but also, particularly, informal) peer interactions is an important element, enabling students to develop and manage their own selfregulated learning (SRL) strategies (Zimmerman, 1989), something especially challenging within blended DL approaches, where student-student contact has been shown to influence SRL and enhance academic achievement (Lim et al., 2020).

Gather.town (GT), from Gather, is an intuitive, online, proximity-based video-conferencing software which offers participants the ability to move freely within a 2-D, pre-designed space where users can access private 'rooms', interact with shared documents and files (including pre-recorded videos), co-create using a wide variety of available 'objects' and connect with one another. Currently, the platform offers full design features and access for up to twentyfive participants in any space for free, with no limit on the number of spaces a user can create. Although used predominantly for conferences with much success (Samiei et al., 2020; Fischer et al., 2021), there is, to date, very limited literature on its use as a learning tool. Despite this, GT offers educators the ability to pre-design learning spaces specific to their audience, to communicate effortlessly between entire spaces and small groups and to provide tailored support to students and/or student groups as they progress through the activities in a DL synchronous environment. In this manner, it is proposed that GT could present an opportunity for students to derive the benefits of synchronous sessions, which provide opportunities for peer-peer communication and development of a sense of identity within their learning community (Themeli, 2016), as well as offer the flexibility and tailored nature of self-paced learning to enable students to develop their SRL strategies (Tullis and Benjamin, 2011).

This case study aims to investigate the practical usefulness of GT in the context of a researchintensive UK university and is focused on a student cohort traditionally considered 'technologically challenged'. It also aims to determine the perceptions of both students and educators as to its effectiveness as a learning tool for teaching a practical skill. These students were specifically selected, as the majority are active farmers based in remote locations in rural Ireland/Northern Ireland and generally demonstrate unfamiliarity with technology (identified 
from previous interaction), thus enabling assessment of the platform in relation to a less capable and physically distant audience. From the clear but limited results obtained, we propose GT as a useful novel resource, enjoyed by both students and educators, which can be used to supplement face-to-face synchronous sessions in order to support learning communities at a distance and provide tailored, self-paced learning with the benefits of SVC, particularly in relation to teaching practical-based skills.

\section{Implementation and evaluation}

To determine the effectiveness of GT as a platform for practical skills education, Dr McClure and a team of demonstrators delivered a series of five, weekly, one-hour data analysis sessions via the site to a cohort of thirty-eight final-year (fourth-year) students within the 'Research Project' module of the BSc Agricultural Technology course at Queen's University Belfast (QUB). The cohort was separated into two groups (of nineteen students each) - to avoid the need for a service fee - ensuring that no more than twenty-five individuals were accessing the space at any one time. Dr McClure and two demonstrators taught the sessions - delivered back to back to each of the cohorts - each focusing on an element of the data analysis process. Although each session was open to students via a unique link, passwords could have been created and altered weekly to ensure restricted access to the course content.

Each week, Drs McClure and Williams (hereafter referred to as "we") arranged the online teaching environment with the appropriate materials for the students to engage with. The specifically designed space consisted of three private 'rooms', each containing information and materials related to a specific task, each attended by an educator and each labelled appropriately within the site to direct the students (see figure 1). Interactive materials consisted of pdf. guides to the task, instructional videos (accessible only to the students) and links to websites and anonymous quizzes via MS Forms. A video guide for map-building, as well as embedding 'objects' - such as posters, videos, surveys etc. to which participants can interact - within the environment and a general introduction to GT, can be found on the official YouTube Channel.

Prior to the five-week programme, we introduced students to the GT platform via the University's virtual learning environment (VLE), 'Canvas', with an online guide (see appendix I). We also described the sessions' format and overall Learning Outcomes, via Canvas, in advance of the sessions. For the overall assignment, students were to complete five individual - but related - tasks, and each week the three 'rooms' were dedicated to the tasks appropriate to the students' overall progression (as monitored by weekly anonymous polling). Throughout each week, we made interactive resources available to the students, so that they could access them asynchronously, and encouraged them to compile questions and determine limitations prior to the GT sessions, where they could address these, either with peers in groups or with the educators directly.

At the beginning of each session, Dr McClure provided a brief introduction to the particular task of the week via a 'podium' (a GT object), which enabled the educator to broadcast to all individuals within the space, regardless of whether or not participants were in a private space. Following this, students had the freedom to interact with the available resources, the educators and/or their peers in their own manner (example engagement can be seen in figure 1). This 
format 1) enabled students to choose, and engage specifically with, the material most relevant to their individual progress and 2) provided more of an opportunity for one-to-one assistance and peer support than would have been possible through other SVC formats. Educators had the facility to message each other privately during the session, to assist necessary real-time adaptations to the educational environment to better suit students, as well as to provide 'global' announcements in order to support the structure of the sessions. Following each session, Dr McClure provided a written summary on Canvas, in addition to any recorded material from the session's introduction and task overview for the students to access.

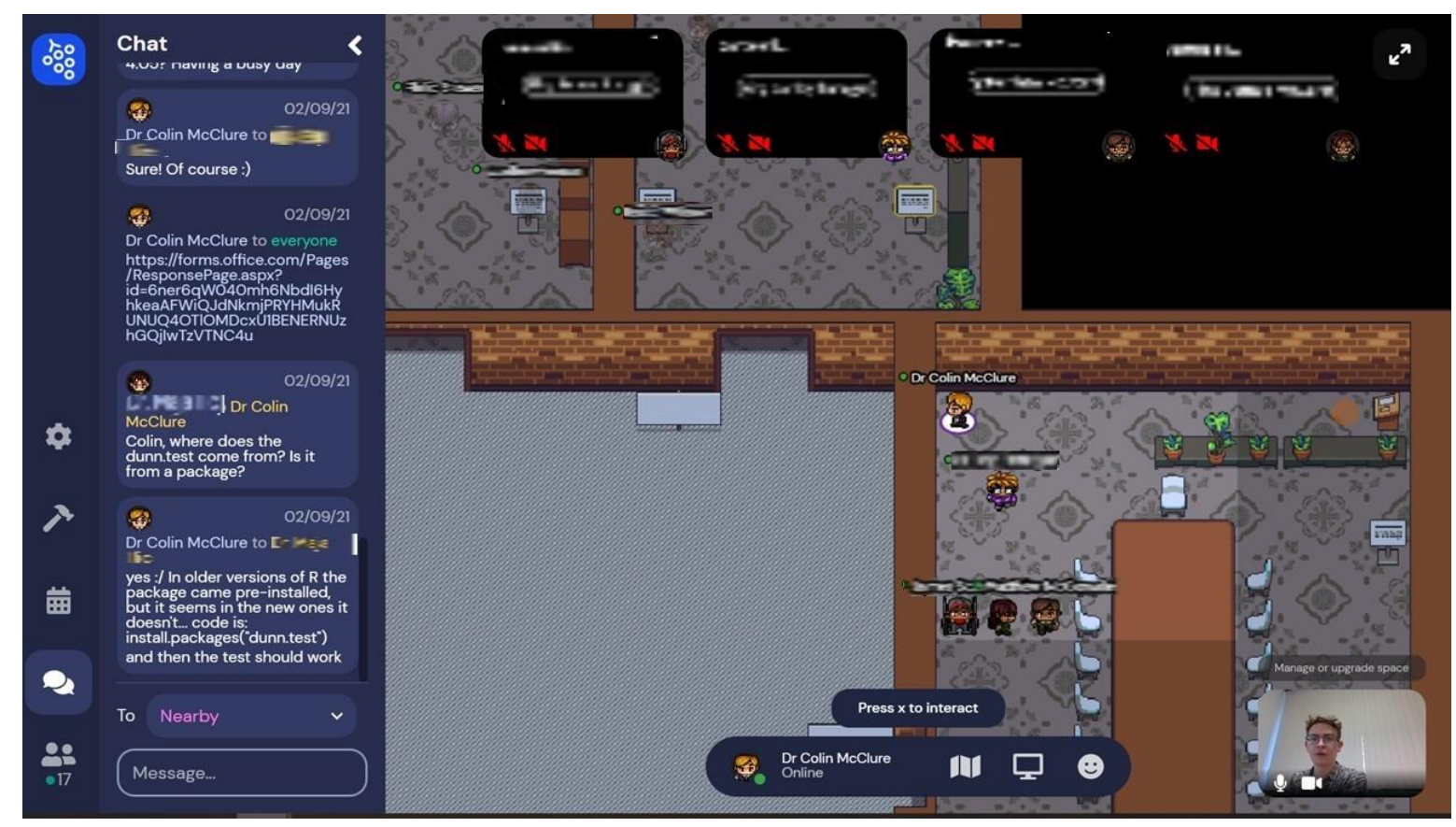

Figure 1: The GT environment designed for the data analysis sessions.

An anonymised snapshot of a live GT session in action - with three educators and fourteen students - demonstrating the various functionalities of the platform and enabling students to access materials appropriate for, and relevant to, their individual stage. The highlighted tiles surrounding the user ( $\mathrm{Dr}$ Colin McClure) indicate a private space the user is presenting to.

To evaluate the perception of GT, we delivered a short, anonymous survey via MS Forms to the students and to the educators involved, to capture their impression of the platform as an educational resource. Both surveys were distributed between the second and fourth sessions of the programme (i.e., 2 February to 15 February 2021) and are available in appendices II and III. We asked respondents to provide their perspectives of GT in comparison to other DL software and of face-to-face sessions, as well as to rank in order of importance six features of the GT software: i) ability to discuss with educator; ii) ability to discuss with peers; iii) placement of interactive resources; iv) ability to go where you want; v) ability to access private spaces; vi) aesthetics of the programme. Students did not complete the assignment by the time this manuscript was submitted for publication, and the ability of the students was not directly assessed. 


\section{Results}

Students who engaged in GT sessions indicated that they enjoyed using the platform, giving the platform an overall rating of 3.57 / 5 stars overall $(n=7)$, while educators rated it $4 / 5$ stars on average $(n=5) .86 \%$ of student respondents stated that the software was the same or better (i.e., 'same', 'somewhat better', or 'much better') than alternative distance-learning software (figure 2A), while only $29 \%$ indicated that they preferred the GT sessions to face-to-face sessions (figure $2 \mathrm{~B}$ ).

\section{Perspectives of GT compared to...}
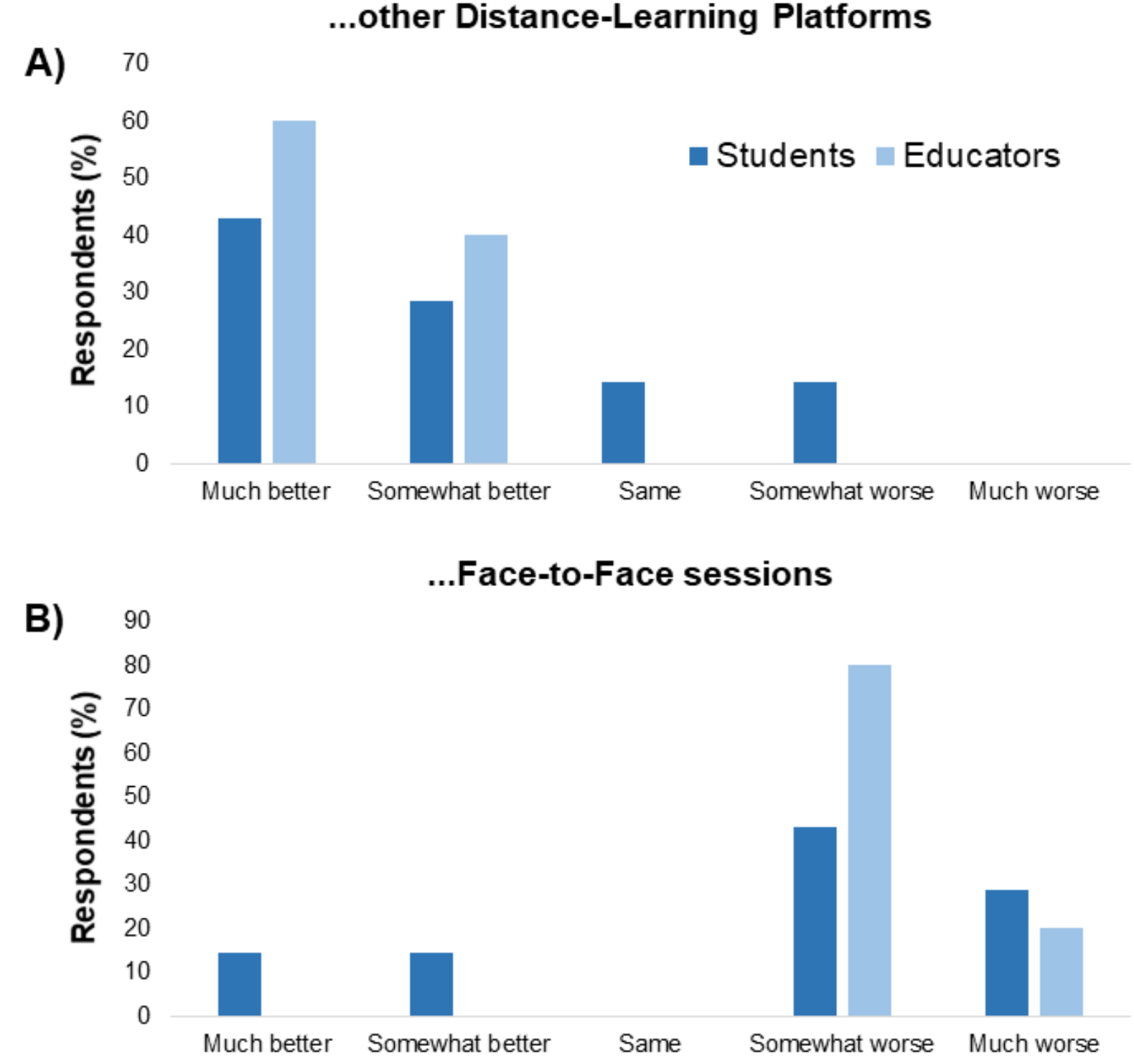

Figure 2: Student and Educator perceptions of the GT platform in relation to a) other commonly used distance-learning software (e.g., MS Teams), and b) face-to-face sessions. 
These opinions were supported by the free-text comments students submitted to explain their selection; one respondent stated:

"... can speak to lectures [sic] about our issues / problems more freely than in front of the whole class on ms teams however still more difficult than face to face" - Student 3

Students particularly identified the benefits of using GT for learning practical skills, which require more structured, self-directed learning with continuous, individualised feedback (Vogel and Harendza, 2016); another student stated:

"Much the same as MS Teams but think it better for practical work. Its [sic] harder than face to face but is probably the best alternative due to Covid-19" - Student 2

Overall, the impression of GT was positive within this student cohort, as $71 \%$ of respondents indicated they would like to have more educational sessions in their course delivered via the platform.

Preference for the platform was also shared by educators where $100 \%$ of respondents stated that more education sessions should make use of the system. However, in contrast to the students, $100 \%$ of educators felt that GT was not an equally effective alternative for face-toface sessions, while all respondents indicated a preference for the system over more static SVC learning platforms (figures $2 \mathrm{~B}$ and $2 \mathrm{~A}$ respectively). These opinions were furthered by the comments of the individual educators, who identified the novelty of the platform and its ability to increase engagement between both students and educators:

"The software allows a good virtual interaction between participants in a session and it makes learning more fun than the other distance learning software" - Educator 2

"I found that gather.town allowed for much more engagement than Teams (used for both for the same purpose)" - Educator 3

Another educator went further to identity particular aspects of the GT platform they felt supported the learning experience for the students:

"Having separate rooms with demonstrators, the option to watch videos and see other content, was in my opinion very helpful and it provided more options to the students to both learn on their own, but also to interact better with demonstrators, as they could directly speak to them if they had specific questions" - Educator 4

To explore this further, both students and educators were also asked (optional) to rank the importance of various elements which GT enabled for the users. These elements included those relating to communicating with others (both educators and student peers), the use of interactive materials, the ability to move within the space and the aesthetics of the platform (figure 3, A-C). 


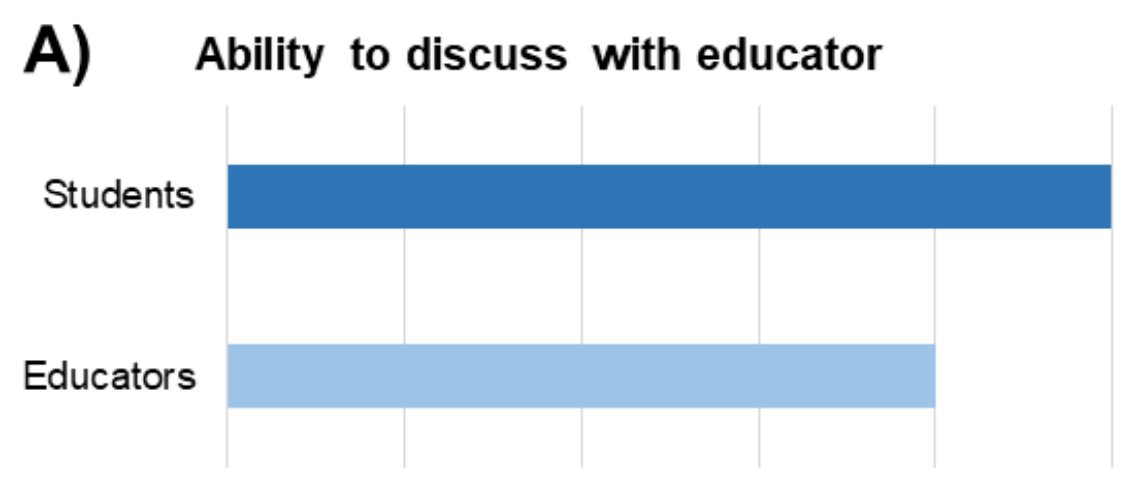

\section{B) Placement of interactive resources}

Students

Educators
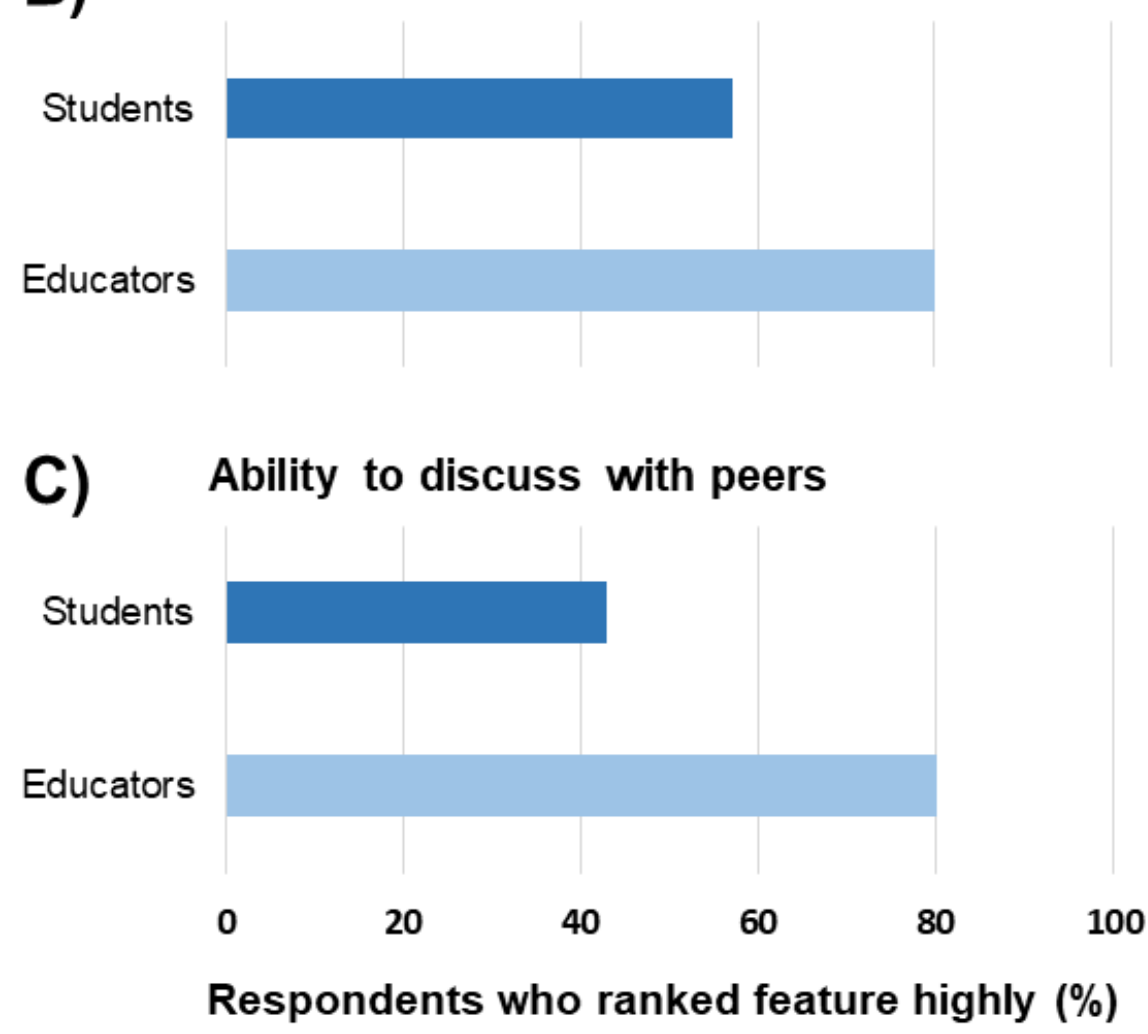

Figure 3. Top three GT features as ranked by both educators and students and the proportion of respondents who ranked each element 'highly' (i.e., within their top three of six positions). Statements shown are those presented in student-directed surveys and were altered accordingly for educators (see Appendices II and III for details). Full rankings for all features can be found in Appendix IV.

The ability to discuss with educators was ranked by both groups as the most important element offered by GT and the ability to interact with pre-prepared materials was agreed as the second most important aspect of the platform (figure $3 \mathrm{~A}$ and $\mathrm{B}$ ). Both groups thought ability to discuss between peers was a close third (figure $3 C$ ), but, while educators thought the ability to move around would be the least important element of GT, students were in agreement that the aesthetics were not important (see appendix IV). 
It was clear that, although not ranked as the most significant element, interaction between peers was an important feature of the GT experience, particularly within this context of practical skill learning; one student stated:

"I enjoy gather town as their is [sic] more options to talk and interact with peers however I do miss the classroom experiences however that cannot be helped in this pandemic" - Student 1

This comment highlights the importance of how peers can interact in GT, either in private video-calls - as individuals or groups - or within the instant message function, which enables students to learn from each other, to collaborate to complete tasks or to share self-paced and $\mathrm{SRL}$ strategies. This aspect was also recognised by the educators, who appreciate the importance of personal and individualised conversation in the formation and strength of learning communities:

"I think GT is better than (MS) Teams because the interaction experience is more realistic - as it facilitates more dynamic person-person engagement' - Educator 1

\section{Outlooks and limitations}

The COVID-19 pandemic, as well as the current economic landscape of HE within the UK and beyond, has forced HEls to evolve and deliver distance-learning (DL) programmes and modules in place of traditional face-to-face sessions (Ali, 2020). This adjustment brings a variety of challenges, particularly within the teaching of practical-heavy subjects, when relying on synchronous video-conferencing (SVC) for much of live learning (Dost et al., 2020). This case study demonstrates GT, when compared to a common SVC software (MS Teams), to be a learning resource preferred by both students and educators when teaching a practical-based skill in a UK research-intensive university (figure 2).

The responses obtained from both students and educators from this study indicate that the primary advantages of GT are its ability to support tailored and self-paced learning, enabling students to interact with educators on a more informal basis, and the opportunity to use the designed resources in an individualised manner. Additionally, both groups emphasised that an important element of the platform was its ability to offer peer-discussion opportunities and facilitate engagement between participants (figure 3). Peer-to-peer learning has been demonstrated to support deeper learning (Hildson, 2014), inform students' SRL strategies and support the development and strength of learning communities, which can be difficult to foster in a DL environment (Themeli, 2016; Lim et al., 2020).

This case study therefore demonstrates how GT could be used as a means of supporting learning communities and of providing opportunities for tailored learning alongside other synchronous and asynchronous sessions. It is important to consider, however, that these elements may be encouraged to some extent through a range of other technologies; for example, the use of student-led breakout rooms in MS Teams (Al-Samarraie, 2019; Saltz and Heckman, 2020), although it is the authors' opinion that GT offers the most effective opportunities for informal communication - important for students to self-pace their learning (Rhode, 2009). While acknowledging this, it is important to understand the practical limitations of using this platform for education sessions in place of other SVC systems. First is to note 
the various minor audio and video glitches which occur when using GT (as detailed by Samiei et al., 2020), but these can usually be resolved by exiting and re-entering the session, simply by refreshing the web page or pasting the session's url into the web browser. Another concern, as with all SVCs, are the bandwidth demands to run the platform. This, of course, will depend on the variety and quantity of resources educators provide for their sessions (please note: poster objects require high-bandwidth), but, from personal experience, Dr McClure was able to join and interact with a session with a 2-3 Mbps connection, which is comparable to the MS Teams requirement - i.e., $1 \mathrm{Mbps}$ (Microsoft, 2020). Despite these low requirements, an educator did experience connectivity issues, stating:

"you will need good internet connectivity for the full experience otherwise the software freezes often" - Educator 2

This, however, may be on account of the specific context of the study, as both students and educators are often in rural locations within Northern Ireland, which exhibit slower connectivity in general (Ofcom, 2018). It is important to note here, however, that access to the GT platform, to the authors' knowledge, is not restricted when using foreign VPNs, enabling students to engage with the platform from any location.

Arguably, the most significant limitation of GT currently is the number of participants who can use the software at any time, a concern raised by one educator:

"but it is limited (unless using Premium version) by the number of people who can access it simultaneously" - Educator 3

Owing to the exploratory approach of this evaluation, the case study was completed without cost to the education team, enabling up to twenty-five users to access the learning space at any one time. However, this can be increased on a per-user basis (see https://gather.town/pricing for details).

Furthermore, it is important to recognise accessibility concerns when incorporating GT for students with visual impairments, who will find it difficult to navigate the 2-D space unassisted, or neurodiverse students who may find the novel environment and the number of objects and/or moving avatars in the environment overwhelming (Kent, 2015). Additionally, current access to the complete suite of facilities offered by GT can only be achieved when using the laptop/desktop version of the platform rather than that for a mobile phone. This is of concern, considering the increasing desire of HE students to use smartphones as their preferred learning devices (Ahmad, 2020). Given these accessibility issues, educators, prior to deploying this tool, should give careful consideration to whether to implement it in a programme and, if they do decide to use it, to plan appropriately to overcome potential difficulties.

With these limitations in mind, it is important to consider what GT can offer to the educational landscape of HE during and beyond the pandemic. What is clear to the authors as well as the participants, is that GT is not a direct replacement for face-to-face synchronous learning; nor is it to be used as a sole teaching tool. As the data here represent, GT can be used as a resource complementary to other asynchronous and synchronous $\mathrm{DL}$ - and even face-to-face - educational approaches, allowing students to maintain a connection with their cohort of learners and to take advantage of more tailored and self-paced learning. Such a blended teaching approach has many benefits, for both educators and for students, and seems to be 
the clear and preferred direction of HE following the COVID-19 pandemic, where GT is sure to be a useful feature in all educators' toolkits (Amir et al., 2020; Paudel, 2021), as enthusiastically stated by one of the educators in this study:

"GT is a great idea and delivers an exciting alternative to static video call platforms such as MS Teams" - Educator 1

\section{Reference list}

Ahmad, T. (2020) 'Student perceptions on using cell phones as learning tools: Implications for mobile technology usage in Caribbean higher education institutions.' PSU Research Review, 4(1), 25-43. Available at:

https://www.emerald.com/insight/content/doi/10.1108/PRR-03-2018-0007/full/pdf (Accessed: 20 May 2021).

Al-Samarraie, H. (2019) 'A Scoping Review of Videoconferencing Systems in Higher Education: Learning Paradigms, Opportunities, and Challenges.' International Review of Research in Open and Distributed Learning, 20(3), 1-19. Available at: https://files.eric.ed.gov/fulltext/EJ1223628.pdf (Accessed: 07 February 2021).

Ali, W. (2020) 'Online and Remote Learning in Higher Education Institutes: A Necessity in light of COVID-19 Pandemic.' Higher Education Studies, 10(3), 16-25. Available at: https://files.eric.ed.gov/fulltext/EJ1259642.pdf (Accessed: 25 January 2021).

Amir, L.R., Tanti, I., Maharani, D.A., Wimardhani, Y.S., Julia, V., Sulijaya, B. and Puspitawat, R. (2020) 'Student perspective of classroom and distance learning during COVID-19 pandemic in the undergraduate dental study program Universitas Indonesia.' BMC Medical Education, 20, 392. Available at:

https://bmcmededuc.biomedcentral.com/track/pdf/10.1186/s12909-020-02312-0.pdf (Accessed: 25 January 2021).

Azizan, F.Z. (2010) 'Blended learning in higher education institution in Malaysia.'

Proceedings of Regional Conference on Knowledge Integration in ICT, 454-466. Available at: http://library.oum.edu.my/oumlib/sites/default/files/file_attachments/odlresources/4334/blended-learning.pdf (Accessed: 07 February 2021).

Dhawan, S. (2020) 'Online Learning: A Panacea in the Time of COVID-19 Crisis.' Journal of Educational Technology Systems, 49(1), 5-22. Available at:

https://journals.sagepub.com/doi/pdf/10.1177/0047239520934018 (Accessed: 25 January 2021).

Dost, S., Hossain, A., Shehab M., Abdelwahed A., and Al-Nusair., L. (2020) 'Perceptions of medical students towards online teaching during the COVID-19 pandemic: a national crosssectional survey of 2721 UK medical students.' BMJ Open, 10:e042378. Available at: 
https://bmjopen.bmj.com/content/bmjopen/10/11/e042378.full.pdf (Accessed: 25 January 2021).

Fisher, J.B., Keenan, T.F., Buechner, C., Shirkey, G., Perez-Quezada, J.F., Knox, S.H., Frank, J.M., Runkle, B.R.K., and Bohrer, G. (2021) 'Once upon a time, in AmeriFlux.' Journal of Geophysical Research: Biogeosciences, 126: e2020JG006148. Available at: https://agupubs.onlinelibrary.wiley.com/doi/epdf/10.1029/2020JG006148 (Accessed: 21 February 2021).

Harry, K. and Perraton, H. (1999) 'Open and distance learning for the new society.' In: Higher Education Through Open and Distance Learning. $1^{\text {st }}$ Edition. London and New York: Routledge, 1-12. ISBN: 9780203018569

Hilsdon, J. (2014) 'Peer learning for change in higher education.' Innovations in Education and Teaching International, 51(3), 244-254. Available at:

https://www.tandfonline.com/doi/abs/10.1080/14703297.2013.796709 (Accessed: 07 February 2021).

Kaplan, A.M. and Haenlein, M. (2016) 'Higher education and the digital revolution: About MOOCs, SPOCs, social media, and the Cookie Monster.' Business Horizons, 59(4), 441450. Available at:

https://www.sciencedirect.com/science/article/pii/S000768131630009X?casa_token=ue2klY 7e9ukAAAAA:PBM7LnWZoJXwSZJPXPa7CMIlct4YxPQfN_mwwLgvJ3TT_KpXj43JxgF8A1CxhmeQ3x6esxw0g (Accessed: 25 January 2021).

Kemp, N. and Grieve, R. (2014) 'Face-to-face or face-to-screen? Undergraduates' opinions and test performance in classroom vs. online learning.' Frontiers in Psychology, 5, 1-11. Available at: https://www.frontiersin.org/articles/10.3389/fpsyg.2014.01278/full (Accessed: 07 February 2021).

Kent, M. (2015) 'Disability and eLearning: Opportunities and Barriers.' Disability Studies Quarterly, 35(1). Available at: https://dsq-sds.org/article/view/3815/3830 (Accessed: 20 May 2021).

Lim, C., Ab Jalil, H., Ma'rof, A. and Saad, W. (2020) 'Peer Learning, Self-Regulated Learning and Academic Achievement in Blended Learning Courses: A Structural Equation Modeling Approach.' International Journal of Emerging Technologies in Learning (iJET), 15(3), 110125. Available at: https://online-journals.org/index.php/i-jet/article/view/12031/6509 (Accessed: 07 February 2021).

Microsoft (2020) Prepare your organization's network for Microsoft Teams. Available at: https://docs.microsoft.com/en-us/microsoftteams/prepare-network (Accessed 24 February 2021).

Ofcom (2018) Connected Nations 2018: UK Report. Available at: https://www.ofcom.org.uk/ data/assets/pdf file/0020/130736/Connected-Nations-2018main-report.pdf (Accessed: 24 February 2021).

Paudel, P. (2021) 'Online education: Benefits, challenges and strategies during and after COVID-19 in higher education.' International Journal on Studies in Education (IJonSE), 3(2): 
70-85. Available at: https://www.ijonse.net/index.php/ijonse/article/view/32/pdf (Accessed: 25 January 2021).

Rhode, J. (2009) 'Interaction Equivalency in Self-Paced Online Learning Environments: An Exploration of Learner Preferences.' The International Review of Research in Open and Distributed Learning, 10(1). Available at: https://files.eric.ed.gov/fulltext/EJ831712.pdf (Accessed: 07 February 2021).

Saltz, J. and Heckman, R. (2020) 'Using structured pair activities in a distributed online breakout room.' Online Learning, 24(1), 227-244. Available at:

https://olj.onlinelearningconsortium.org/index.php/olj/article/view/1632/908 (Accessed: 21 February 2021).

Samiei, M., Weis., C., Schiavo, L., Chavdarova, T. and Yousefi, F. (2020) 'Convening during COVID-19: Lessons learnt from organizing virtual workshops in 2020.' arXiv:2012.01191v1. Available at: https://arxiv.org/pdf/2012.01191.pdf (Accessed: 07 February 2021).

Themeli, C. and Bougia, A. (2016) 'Tele-proximity: Tele-community of Inquiry Model. Facial Cues for Social, Cognitive, and Teacher Presence in Distance Education.' International Review of Research in Open and Distributed Learning, 17(6), 145-163. Available at: http://www.irrodl.org/index.php/irrodl/article/view/2453/3950 (Accessed: 21 February 2021).

Tullis, J.G. and Benjamin, A.S. (2011) 'On the effectiveness of self-paced learning.' Journal of Memory and Language, 64(2), 109-118. Available at:

https://www.ncbi.nlm.nih.gov/pmc/articles/PMC3079256/pdf/nihms-260878.pdf (Accessed: 07 February 2021).

Vickers, H. (2017) 'Number of international students studying online soars.' Available at: https://universitybusiness.co.uk/Article/international-students-studying-online-courses-onthe-rise/ (Accessed 21 February 2021).

Vogel, D. and Harendza, S. (2016) 'Basic practical skills teaching and learning in undergraduate medical education - a review on methodological evidence.' GMS Journal for Medical Education, 33(4), 2366-5017. Available at:

https://www.egms.de/static/en/journals/zma/2016-33/zma001063.shtml (Accessed: 07 January 2021).

Xu, D. and Xu, Y. (2019) 'The Promises and Limits of Online Higher Education.' Available at: https://tacc.org/sites/default/files/documents/2019-03/the-promises-and-limits-of-onlinehigher-education.pdf (Accessed 21 February 2021).

Zimmerman, B.J. (1989) 'A social cognitive view of self-regulated academic learning.' Journal of Educational Psychology, 81(3), 329-339. Available at: https://www.researchgate.net/profile/Barry-Zimmerman2/publication/232534584_A_Social_Cognitive_View_of_SelfRegulated_Academic_Learning/links/549483c40cf20f487d2c12a4/A-Social-Cognitive-Viewof-Self-Regulated-Academic-Learning.pdf (Accessed: 07 February 2021). 


\section{Appendix I}

\section{\%。 Gather}

\section{Welcome to Gather!}

Gather is a wonderful new tool for getting to both explore and chat with other people. It is also a very new tool and has a few quirks. This document is to help you with the basics so you can discover and play on your own.

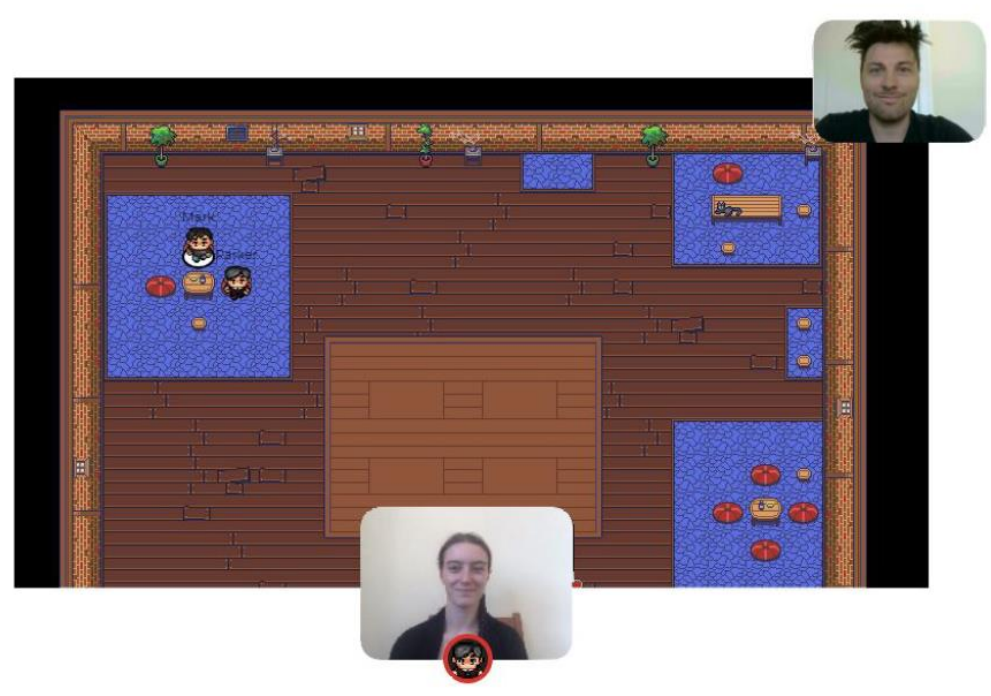

\section{What you need:}

- A desktop/laptop with a mic and camera.

- A web browser (Chrome or Firefox recommended).

- We strongly recommend using headphones to help prevent feedback.

- That's it! There's nothing to install, no software to download.

\section{How it works:}

- Gather is a video chat platform that has avatars move around a map. As you get close to other avatars, your videos will pop up and you will be able to chat.

- Move around the space using the arrow keys.

- By moving your avatar around you can have spontaneous conversations with those around you. These can be either one-on-one or small groups, depending on how many people are around your avatar.

- When your avatar moves closer to an interactable object, there will be a notification that shows up saying 'Press $x$ to interact with -object-'. This can range from informational flyers, playable arcade games, integrated Zoom meetings and more! 


\section{Icon explanation:}

Screen sharing ability

Change your avatar character and clothing

Mini map to preview the space you're in

Raise hand feature: good for $Q \& A$ in keynotes or classrooms

Opens the settings menu:

- Change Name

- Change Audio/Video Devices

- Respawn button to return to start

- Click for Mod Settings: Change room password, change mod message, toggle force mute whole space

\section{Not-So-Obvious Features:}

Here are some things you might find useful but aren't immediately obvious.

- There is a messaging feature that allows you to message people in four ways:

1. individually by clicking on their name in the participant panel,

2. locally to the people you are video-chatting with,

3. room chat (must be requested) with all the people in the current room you are in,

4. globally to all the people in your map.

- There is a locate feature to find others by clicking their name in the participant panel.

- Interaction distance is also sometimes altered by designated private spaces. This allows conversations to include only people inside that space.

- Want to full screen someone else's video? Just click on their video.

- Talking to a group of people? Click the down arrows centred below the videos to shift into grid view.

\section{Privacy Features:}

We have three ways for you to control who has access to your map:

- You can add a password via the mod setting for a room.

- If you want to allow only certain people, you can create an email whitelist here.

- Domain whitelists allow the moderator to allow entry into the space for all those who share the same email domain (e.g., something@gather.town).

For managing people who are already in the space, we have the following options:

- Any moderator has the ability to ban individuals during the event

\section{Technical difficulties:}

- Refreshing the page will fix most things!

- If that doesn't work, try muting and unmuting your mic and camera in Gather.

- Check if your browser permitted camera and mic access

- Additional troubleshooting at https://gather.town/video-issues

Available from http://gather.town 


\section{Appendix II}

Gather.town Class Survey - Student

Thanks for attending the online session on Gather.town (http://gather.town).

Please complete the short anonymous survey online to provide your perspectives on the platform for teaching.

Your participation in this questionnaire is completely voluntary and you may opt not to submit your responses at any time prior to clicking the 'submit' button following your completion of the final question. Should you wish to do so, simply close this window. By completing this survey, you are consenting to participate in this study and for the data to be used in presentations or publications resulting from this work. Any information that you do submit will be stored within a password-protected folder on an encrypted QUB file server, in compliance with data protection legislation.

${ }^{*}$ Required

1. How would rate gather.town (http://gather.town) as an educational platform from your experience? *

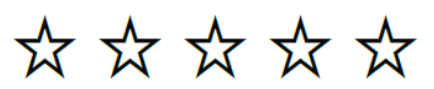

2. How would you rate gather.town (http://gather.town) as an educational platform in comparison to... *

Much better $\begin{gathered}\text { Somewhat } \\ \text { better }\end{gathered} \quad$ Same $\quad \begin{gathered}\text { Somewhat } \\ \text { worse }\end{gathered}$ Much worse

...other distance

learning software (e.g.

MS Teams Meetings)

...face-to-face sessions

3. Please comment on the reasons for your selections above:

4. Please rank the following elements of the gather.town (http://gather.town) session in the order you found them most useful: TOP = Most useful; BOTTOM = least *

i. Placement of interactive resources

ii. Ability to discuss with peers

iii. Ability to discuss with lecturer / demonstrator

iv. Ability to access private spaces 
v. The aesthetics of the platform

vi. Ability to go where you want

5. Would you like to see more sessions delivered via gather.town in your course? *

- Yes

- No

- Not sure

6. If you have any final comments on gather.town as an educational system, please write them below: 


\section{Appendix III}

Gather.town Class Survey - Educator

Thanks for demonstrating for the online session on Gather.town (http://gather.town).

Please complete the short anonymous survey online to provide your perspectives on the platform for teaching.

Your participation in this questionnaire is completely voluntary and you may opt not to submit your responses at any time prior to clicking the 'submit' button following your completion of the final question. Should you wish to do so, simply close this window. By completing this survey, you are consenting to participate in this study and for the data to be used in presentations or publications resulting from this work. Any information that you do submit will be stored within a password-protected folder on an encrypted QUB file server, in compliance with data protection legislation.

${ }^{*}$ Required

1. How would rate gather.town (http://gather.town) as an educational platform from your experience? *

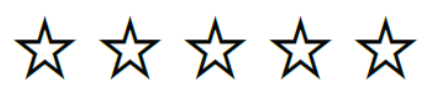

2. How would you rate gather.town (http://gather.town) as an educational platform in comparison to... *

Much better $\begin{gathered}\text { Somewhat } \\ \text { better }\end{gathered} \quad$ Same $\quad \begin{gathered}\text { Somewhat } \\ \text { worse }\end{gathered}$ Much worse

...other distance

learning software (e.g.

MS Teams Meetings)

...face-to-face sessions

3. Please comment on the reasons for your selections above:

4. Please rank the following elements of the gather.town (http://gather.town) session in the order you found them to be most useful for your students: TOP = Most useful; BOTTOM = least *

i. Placement of interactive resources

ii. Ability to discuss with peers

iii. Ability to discuss with lecturer / demonstrator 
iv. Ability to access private spaces

v. The aesthetics of the platform

vi. Ability to go where you want

5. State how you agree with the statement that Gather.town (http://gather.town) is a more effective platform to deliver the following educational practices over standard videoconferencing software... *

\begin{tabular}{|c|c|c|c|c|c|}
\hline & $\begin{array}{l}\text { Strongly } \\
\text { Agree }\end{array}$ & Agree & Neutral & Disagree & $\begin{array}{l}\text { Strongly } \\
\text { disagree }\end{array}$ \\
\hline Delivering Lectures & & & & & \\
\hline Delivering Practicals & & & & & \\
\hline Marking Assignments & & & & & \\
\hline $\begin{array}{l}\text { Communicating with } \\
\text { Students }\end{array}$ & & & & & \\
\hline
\end{tabular}

6. Do you think more educational sessions should be delivered via gather.town? *

- Yes

- No

- Not sure

7. If you have any final comments on gather.town as an educational system, please write them below: 


\section{Case Studies}

\section{Appendix IV}

Students

Educators

A) Ability to discuss with lecturer / demonstrator
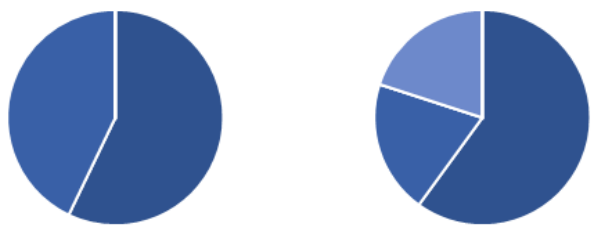

B) Ability to discuss with peers
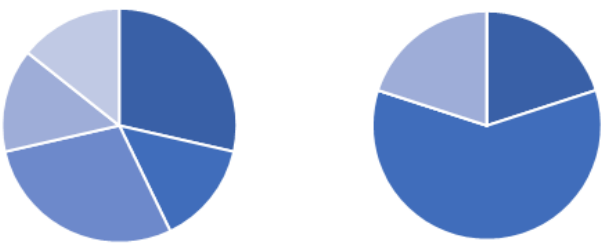

C) Placement of interactive resources
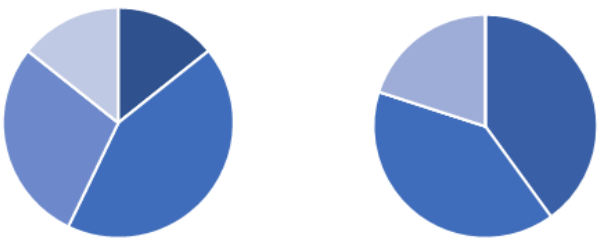

\section{Students}

\section{Educators}

D) Ability to go where you want

\section{Rank}

1 st

2nd

3rd E) Ability to access private spaces

4th

5 th

6th

F) The aesthetics of the platform
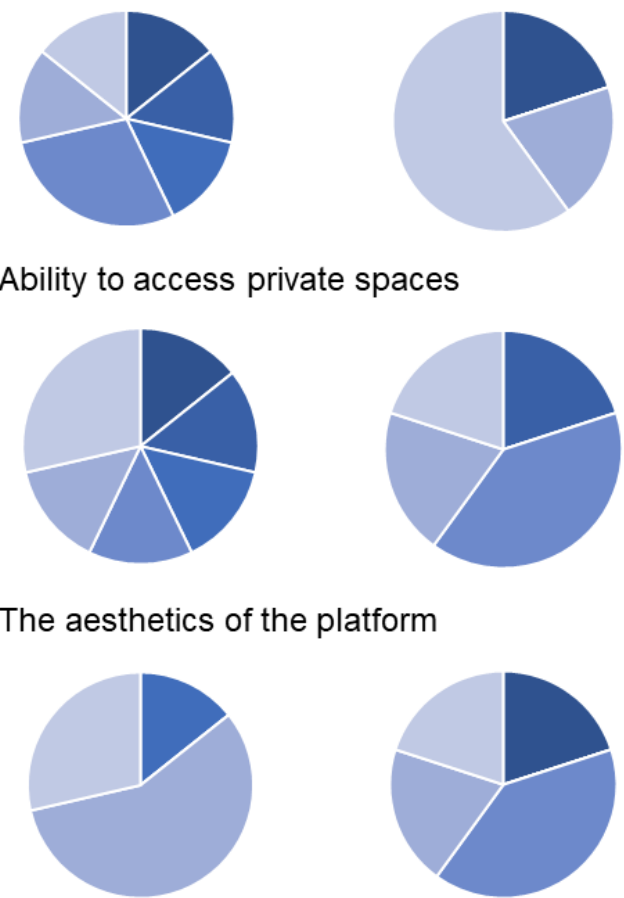

Figure A1. Proportion of respondents ranking of various elements of the GT system $(A-F)$ out of a total of six. Statements shown are those presented in student-directed surveys and were altered accordingly for educators (see Appendices II and III for details). 